\title{
Urdimento
}

\section{O PRODUTOR E O PRODUTO NO TEATRO DE GRUPO}

\author{
Flávia Janiaski ${ }^{1}$
}

Resumo

Opresenteartigoapresentaumareflexão crítica sobre a figura do produtor cultural inserido no universo do teatro de grupo no contexto de uma contemporaneidade definida como pós-moderna, onde fica difícil delimitar o lugar social da arte, e a tênue linha que existe entre o que é produto artístico e o que é produto de mercado. Neste contexto torna-se importante delimitar qual o lugar do produtor teatral que está inserido dentro de um grupo de teatro e que participa do seu processo de criação artística.

Palavras-chave: produtor cultural, mercado, pós-modernidade, teatro de grupo.

No contex to de uma contemporaneidade definida como pós-moderna, fica difícil delimitar o lugar social da arte e a tênue linha entre o que é produto artístico e o que é produto de mercado. Segundo o crítico Fredric Jameson, a cultura colapsou com o capital, de tal forma que é impossível separar a lógica da cultura da lógica do mercado. No campo das artes, nada mais choca nada mais escandaliza ninguém, tudo é permissível, tudo é aceitável, o artista não tem o que transgredir, tudo é 'normal'. A cultura da imagem e do simulacro destaca-se, deixando a realidade e o conceito de real em segundo plano.

Partindo desta afirmação e vislumbrando uma realidade onde tudo é produto, tudo é vendável, onde a produção estética está integrada à produção das mercadorias em geral, é importante delimitar qual o lugar do produtor

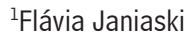
é professora colaboradora do Centro de Artes da Universidade do Estado de Santa Catarina e mestre em Teatro pela UDESC. 


\section{Urdimento}

${ }^{2}$ Segundo Eugênio Barba, Antropologia Teatral "é o estudo do comportamento humano quando 0 ator usa sua presença física e mental em uma situação organizada de representação e de acordo com os princípios que são diferentes dos usados na vida cotidiana" (BARBA, 1999: 74). Ele ainda complementa que a Antropologia Teatral não busca princípios universais, mas indicações que possam vir a ser úteis para o trabalho do ator-bailarino. teatral que está inserido dentro de um grupo de teatro e que participa do seu processo de criação artística. Perguntar qual o lugar deste produtor que tem a função de veicular seu produto cultural, ou seja, fazer a produção de um espetáculo, mas corre o risco de se adaptar ao mercado, constitui um elemento chave para o estudo do fenômeno do teatro de grupo.

\section{Teatro de Grupo}

O teatro de grupo é entendido aqui como aquele teatro que parte de um modelo idealizado de organização grupal que trabalha como um indicativo que movimenta muitas ações criativas e de organização social no âmbito do teatro.

Teatro de grupo implica em uma idéia de um grupo sustentado mais pelo eixo do trabalho artístico e ideológico do que pelas circunstâncias da sobrevivência ou pela realização de um espetáculo específico. Isto é, os elementos de identificação passam pelas vias afetivas e técnicas, funcionam com auto-gestão e tem leituras semelhantes frente aos códigos de criação e produção teatral. Buscam, em geral, uma estabilidade de elenco, através de projetos de longo prazo e de uma organização de práticas pedagógicas, não esquecendo de mencionar a importância de uma ordem ética para o trabalho coletivo.

É um teatro fortemente influenciado pelas idéias do diretor italiano Eugênio Barba (1936-), e seu teatro Antropológico². Barba renegou as formas comerciais de teatro e buscou sempre uma organização baseada em um forte grupo independente. Valorizando a noção de coletivo ele busca uma forma grupal constituída com um referente ideológico comunitário. Em 1964 ele funda em Oslo na Noruega o Odin Teatret - que se muda para Holstebro na Dinamarca em 1966 - com o Odin Barba criou um instituto de pesquisa para a formação do ator, e para desenvolver o trabalho de ator era preciso trabalhar com atores que fizessem parte de um projeto com estabilidade e continuidade, isto seria possível dentro de um grupo, onde os atores não se separassem ao final de uma montagem, por exemplo.

Eugênio Barba acompanhou o trabalho de Grotowski em Opole por cerca de dois anos, entre 1962 e 1964, e foi com ele que Barba "aprendeu" a noção do trabalho grupal, valorizando a noção de coletividade onde a união do grupo está alicerçada em sua ideologia. É certo dizer que o Odin se situa em uma zona periférica em relação ao ambiente artístico, por sua sede se localizar no interior da Dinamarca, no entanto suas ações de disseminar o Teatro Antropológico são muitas e variadas, entre elas podemos destacar a publicação de uma revista teatral; organização de seminários internacionais sobre o trabalho do ator realizando intercâmbios com outros grupos e dedicação de horas diárias para o treinamento do ator. Vale destacar que este treinamento está baseado em uma estrutura coletiva, em um grupo com trabalho contínuo.

0 Produtor e o Produto no Teatro de Grupo. Flávia Janiaski.

Dezembro 2008 - № 11 


\section{Urdimento}

É importante ressaltar que apesar do Odin Teatret receber subvenção do governo dinamarquês, este opera como um grupo independente com fortes características o teatro de grupo, onde cada membro tem projetos individuais dentro dos projetos coletivos. Seu diretor teve iniciativas de caráter pedagógico e fundou a International School of Tehatre Anthropology (ISTA) reunindo especialistas de teatro, antropólogos, sociólogos, entre outros mestres com o intuito de ensinarem os alunos a "aprenderem a aprender" criando um método pessoal e individual de trabalho.

Eugênio Barba sempre teve a preocupação e a prática de realizar intercâmbios com fazedores teatrais do mundo inteiro. Foi, especialmente, através destes intercâmbios que as idéias do Teatro Antropológico e sua cultura de grupo chegaram ao Brasil na década de 1980 e tiveram, ao lado de outras companhias estrangeiras ${ }^{3}$, impacto no ideal de teatro de grupo brasileiro. Na década de 1980 o número de festivais internacionais cresce consideravelmente no Brasil, o que proporciona a visita de inúmeros grupos estrangeiros no país, entre eles o Odin Teatret.

Écerto dizer que a influência que Barba tem no teatro de grupo brasileiro a partir da segunda metade dos anos 80, e em toda América Latina, é grande, uma vez que muitos dos grupos que pertencem a este movimento tomam o Odin e suas práticas como baliza para a construção de projetos grupais.

Neste caso os elementos de identidade coletiva e a realização de uma ação transformadora do sujeito humano através do teatro é central. Neste sentido, Carreira (2006) destaca como resultado mais perceptível da influência do Teatro Antropológico na década de 1980 no Brasil, a criação de uma rede permanente de trocas que promove a transmissão de modelos de trabalho técnico.

O teatro de grupo tem uma estrutura de auto-gestão na qual mescla elementos de identificação afetiva e técnica, no desejo de resistir a um referente hegemônico comercial. Este teatro que prima pela liberdade de criação firma posição frente à indústria cultural e na maioria das vezes busca formas de se manter fora deste sistema comercial. É possível afirmar que o teatro de grupo se apresenta para o os grupos como uma forma de realizar uma reflexão constante, além de propiciar a construção de métodos de formação do ator.

É certo dizer que o movimento de teatro de grupo faz nascer um compromisso de constante reflexão e discussão sobre os alicerces do fazer teatral. Despertando o anseio de arquitetar métodos de formação do ator fundamentados em uma ordem ética para o trabalho em grupo.

Dezembro $2008-\mathrm{N}^{\circ} 11$

0 Produtor e o Produto no Teatro de Grupo. Flávia Janiaski.
${ }^{3}$ Um exemplo disso é a experiência de um dos mais expressivos grupo de teatro do Brasil: o Grupo Galpão (MG). 0 estimulo para a criação de um grupo de teatro para 0 Galpão nasceu de uma oficina realizada pelos alemães Kurt Bildteins e George Froscher membros do Teatro Livre de Munique. Fora este exemplo, podemos destacar ainda que com o fim da ditadura militar os intercâmbios com a Europa aumentaram resultando uma maior circulação de grupos. 


\section{Urdimento}

${ }^{4}$ Rede Brasileira de Espaços e de Criação, Compartilhamento e Pesquisa Teatral, nasceu no ano de 2004 com 0 anseio de proporcionar discussões sobre pesquisa e criação teatral e se constitui em um meio de acessar os grupos de teatro de todo o país.

${ }^{5} 0$ Próximo Ato Encontro Internacional de Teatro Contemporâneo é um espaço para a reflexão e a prática do teatro, onde acontecem oficinas, debates, leituras dramáticas e relatos de experiência. Acontece há cinco anos e na edição de 2006 o destaque foi para a discussão do papel do teatro de grupo.
Desta forma podemos dizer que os aspectos contemporâneos do teatro de grupo estão baseados na relação afetiva, social, política e econômica dos seus integrantes. Na maioria dos casos primando um treinamento contínuo do trabalho de ator através de um elenco estável e que mantêm uma relação de integração; projetos desenvolvidos em longo prazo; preocupação estética e ideológica; desenvolvimento de pesquisa, se tornando um espaço para a experimentação cênica; resistência frente à tendência do teatro comercial e/ ou de modelos hegemônicos.

O conceito de teatro de grupo é mais do que a organização num coletivo. Ele está ligado às dinâmicas internas em torno de um mesmo ideal, o que terá como conseqüência direta a criação de uma linguagem que identifica o grupo. Os trabalhos dentro deste grupo são continuados, o coletivo busca a construção de uma identidade poética.

As dinâmicas e metodologias de cada grupo estão intrinsecamente ligadas aos seus objetivos e suas motivações grupais, estas motivações englobam os desejos individuais de seus integrantes. Quando o grupo delimita o que é o fazer teatral, ele traça os objetivos e metas a serem cumpridos, e são estes objetivos que darão forma ao grupo. Desta maneira quando o grupo de teatro define o que é teatro para ele, e o que vai motivar seu trabalho, é que este grupo cria seu espaço de atuação, estabelecendo seus referentes éticos, seus objetivos e seu plano de ação.

No que se refere à busca por financiamento de seus projetos, este teatro de grupo parte a procura de sistemas alternativos, práticas que rompam à lógica do teatro comercial. Por isso ganha forma a idéia de teatro de grupo como uma alternativa de resistência.

Entre estas alternativas de resistências estão as iniciativas de alguns grupos de destaque na cena nacional que trabalham de acordo com o modelo de teatro de grupo, tais como a criação de movimentos, cooperativas e fóruns de discussão. Entre estes podemos citar o Movimento dos grupos de Investigação Teatral de Porto Alegre, o Movimento Artes Contra a Barbárie de São Paulo, o Movimento de Teatro de Grupos de Minas Gerais, a formação de Cooperativas e de Centro de Pesquisas, entre outros. Iniciativas estas que primam o intercambio e a formação permanente. Vale destacar aqui a criação da Rede Redemoinho ${ }^{4}$ e o Próximo Ato ${ }^{5}$.

\section{Pós-Modernidade e a Lógica de Mercado}

Considerando este ambiente de trabalho teatral - o do Teatro de Grupo - e concordando com Jameson quando ele diz que os fins se separaram dos meios, e que já não existe nada, nem ninguém fora do sistema capitalista, é 
possível concluir que houve uma alteração fundamental no valor do artista em relação à sua obra. Para tudo no mundo existe uma pessoa que venda um valor de mercado e um 'alguém’ que compra.

Neste contexto, o artista passa de criador a mero trabalhador, e a própria cultura é transformada em produto dentro de um sistema de idéias da indústria cultural. O objeto artístico passa a ser, basicamente, um objeto de consumo, antes de qualquer outra coisa. Ou seja, resumindo em uma frase na atual industrial cultural temos os seguintes termos de equivalência: Para cultura - mercado; para artista - cliente; para trabalho - produto. E desta forma vão mercantilizando cada vez mais o fazer artístico.

Na modernidade com o advento do esteticismo e a massiva difusão da reprodução da arte, artistas passaram a se relacionar com empresas gerando produtos que circulam como mercadorias. Ao mesmo tempo a cultura deixou de ser vivida como construção autônoma, e passou a ser representada como parte da fala capitalista. O que nos conduziu, na pós-modernidade, à espetacularização da própria vida, ou como afirmar Guy Debord, o capital transformou os sujeitos em átomos passíveis da mais completa dominação, a imagem se tornou a forma final da reificação. Imagem como mercadoria.

E a cultura na pós-modernidade também é aceita como mercadoria e, portanto, acaba por se transformar em uma "vedete" do consumo na "sociedade espetacular". Só que segundo o autor, nesta sociedade espetacularizada a mercadoria acaba por se transformar em uma fantasia, uma ilusão, e os indivíduos transformados em consumidores passam a consumir ilusões, a comprar fantasias.

A cultura se transformou em um simulacro que fortifica a lógica do capitalismo. Simulacro aqui é entendido como algo exterior e enganador, um conceito que envolve igualdade e diferença, representação e criação, similaridade e contestação, onde tudo é superficial, efềmero e vazio. O termo simulacro pode ser definido por simulação, por um aglomerado de irrealidades onde o valor é igualado ao de realidades, mesmo que os meios de significação através do qual é reconhecido sejam aqueles que ditam seu valor.

Têm-se como princípio na sociedade pós-moderna que a incerteza é a regra, a lógica do simulacro alastra-se por todos os campos da vida humana. As pessoas passam a ser espectadores passivos diante de suas próprias vidas, esta é a transformação advinda da lógica capitalista do lucro a qualquer preço. E uma vez vivendo na lógica do simulacro, onde todos os sujeitos são bombardeados por um exagero de imagens cheias de apelos consumistas, de informações que os exclui da formação de uma identidade própria, estes sujeitos - homens e mulheres - são desobrigados de pensar. Suponho que não há espaço para pensar em uma sociedade onde o efềmero e a espetacularização ditam as regras. 


\section{Urdimento}

Na alienação das imagens televisivas ou nos anúncios publicitários em meio a toda poluição visual que somos submetidos diariamente está claro a intenção de proliferar uma cultura de vicio da imagem que significa mais para o momento social atual do que qualquer outro acontecimento ou conceito. Isso pede uma intensificação na reflexão sobre a relação dos artistas com o mercado capitalista, pois se estamos numa época da sociedade do espetáculo entendida como a mercantilização de todos os gestos humanos, o espaço de autonomia criativa da arte e sua postura de resistência ao status quo estaria questionado.

Em uma sociedade onde os valores que predominam são a liberdade, diversidade e a tolerância, percebemos que esta liberdade diz respeito fundamentalmente à nossa livre opção de consumo. Zygmunt Bauman no seu livro Modernidade e Ambivalência coloca que 'o remédio, como a doença, é totalmente privatizado. Doença é a escassez de consumo, a cura é um consumo ilimitado', (BAUMAN, 1999), no entanto, o consumo não é capaz de suprir todas as necessidades do homem, pois, neste caso, a liberdade de escolha é limitada e excludente.

Seria neste espaço que a arte, especialmente o teatro, trataria de atuar buscando formas de suprir as necessidades do ser humano que não são atendidas pelo mercado. Isso é ainda possível? Existe um espaço intersticial no qual as falas artísticas podem se infiltrar?

Está claro que o mercado não aceita aquilo que ele não pode controlar. Por isso podemos pensar que as estratégias da lógica do mercado são de cooptação das mais diversas falas. Tudo que pode ser revertido para o pensamento do consumo é bem vindo do ponto de vista do mercado. Nossa experiência contemporânea demonstra a extrema habilidade do capitalismo em transformar tudo em mecanismo de consumo, por isso a busca de um gesto que se mantenha independente parece uma quimera, no entanto, isso pode ser considerado uma tarefa central para os criadores que resistem a assumir a inevitabilidade da servidão ao mercado.

\section{O Produtor Teatral}

Escapar da teia do mercado é um problema central para aqueles que tratam de desempenhar a função de produtores teatrais, e isso é chave no contexto do teatro de grupo, uma vez que este ocupa um espaço de resistência. Atualmente, os grupos de teatro têm preocupações quase empresarias que ficam demonstradas quando lidam com termos tais como: competitividade, eficiência, formalização, lucratividade. Estes valores que antes não faziam parte do universo dos grupos de teatro, faz poucos anos já não são tão estranhos no ambiente teatral. Hoje em dia, os grupos de teatro estão envolvidos em 
uma teia que engloba cultura, arte, econômica, políticas públicas, mercado e mercadoria. E é preciso saber lidar com cada um destes elementos, pois negar esse quadro é tentar fugir de forma ingênua.

É neste contexto que emerge a necessidade de pensar a figura do produtor cultural criativo e não comercial. O dilema deste novo produtor está definido pelo fato de que ele sabe que ignorar as leis de mercado é levar sua produção criativa ao fracasso, mas vender seu processo criativo ao mercado é destruir sua arte. Como dar respostas a esse dilema? Cada grupo desenvolve uma dinâmica e uma metodologia própria para enfrentar esse problema, e isso está intrinsecamente ligado aos objetivos e motivações grupais que organizam os desejos individuais. Quando o grupo delimita o que é o fazer teatral ele traça os objetivos e metas a serem cumpridos, e são estes objetivos que darão forma ao grupo.

Trazendo as características pós-modernas e a lógica da indústria cultural para a realidade do Brasil, ou seja, de um país que não conta com políticas públicas de cultura consistentes, que tem no seu discurso oficial um incentivo a profissionalização do produtor cultural para desta forma isentar o Estado de inescapáveis atributos, inclusive constitucionais em uma ausência quase completa de ação. O que resulta em dois víeis básicos: de um lado as fundações culturais distribuídas por todo o país dedicando verdadeiras fortunas a obras físicas ou a espetáculos e eventos com artistas de "renome" nacionais; e de outro lado às empresas que se utilizam do mecenato para humanizar a sua imagem, ou investir em cultura com o significado de estar presente em lugares de muito público, ou estar associado a momentos de emoção, em geral em um ambiente onde o mercado consumidor tem um grande poder aquisitivo.

Ou seja, os principais motivos que levam tais empresas a investir em cultura com o dinheiro do Estado, uma vez que tal subsídio tem origem nas Leis de Incentivo Fiscais, são: o ganho de imagem institucional, a agregação de valor à marca da empresa, o reforço do papel social da empresa e claro os benefícios fiscais.

Os últimos vinte anos nos mostram um Brasil neoliberal que não compreende como dever do Estado gerenciar a cultural, ou mesmo promover alternativas culturais para a população, delegando as Leis de Fomento a função de direcionar recursos públicos por meio de empresas para a classe cultural, tornando o mecenato como parte das estratégias de marketing das empresas. Como conseqüência há um deslocamento do valor da cultura, que desta forma, passa a estar no produto, o que importa é qual o resultado este ou aquele produto cultural pode alcançar para a imagem da empresa, o processo e a pesquisa ficam sempre em segundo plano. 


\section{Urdimento}

As manifestações artísticas ficam desta forma, reduzidas e até mesmo presas aos padrões impostos pelo mercado e a sua lógica de ação, que é a do consumo e do entretenimento. A reificação da cultura capitalista tornou a Indústria Cultural o principal aparelho ideológico da contemporaneidade, "Num mundo governado pela produção de mercadorias, o produto controla o produtor, os objetos têm mais força do que os homens" (FISCHER, 1987: 96), e este campo é sempre conduzido pela produção em série, ou por uma lógica onde o produto é sempre mais importante e valorizado do que o tipo de técnica ou conteúdo que ele tem embutido, assim como a irrelevância de outros fatores como, por exemplo, se este produto provoca algum tipo de transformação social ou não; ou se ele tem ou não algum mérito artístico.

O que nos leva a triste conclusão que a proliferação de gestores de cultura com o seu discurso de livre-mercado são apenas mais artifícios para encobrir o vazio das políticas públicas de cultura. Os grupos de teatro frente estas políticas se vêem "obrigados" a entrar em um jogo de interesses e buscar patrocínios nas empresas. No entanto, para que estes patrocínios sejam acessíveis os grupos precisam criar um produto que se ajuste a imagem da empresa e isso implica na elaboração de uma imagem do grupo que seja atraente para o possível patrocinador. Fazendo isso se corre o risco do produtor teatral ou o grupo de teatro, serem obrigados a adotar uma imagem que preencha as expectativas destas empresas e isso pode gerar uma modificação ou adequação dos valores grupais.

O produtor inserido no grupo teatral comunga com os objetivos e ideais do grupo. Já o produtor que "vem de fora" está descomprometido com o processo de criação artística, ele vê no grupo apenas as possibilidades técnicas e financeiras (utilização dos recursos financeiros, patrocínios, retorno financeiro), e não têm, necessariamente, uma relação orgânica com o trabalho artístico do grupo.

Uma vez que os grupos de teatro possuem um projeto criativo que demanda uma lógica particular que difere das lógicas do mercado, eles precisam de uma pessoa para estabelecer relações entre eles e o mercado, por isso aparece à necessidade de um mediador que é representado pela figura do produtor.

O produtor no grupo de teatro é aquele responsável não só por sua gestão, mais também é quem deve tomar a iniciativa de traçar alternativas para o grupo, planejando e delineando metas. Sua atividade contempla desde o financiamento até a organização de todo trabalho, bem com a realização do espetáculo. É ele que vai criar as condições materiais para a realização do projeto artístico do grupo. 
É neste momento que o produtor que se vê diante do produto e dialogando com este produto vai buscar alternativas de sobrevivência. Vai procurar desenvolver estratégias de divulgação e comercialização que indiquem a negação dos modelos hegemônicos e a busca de sistemas alternativos. O produtor criativo e engajado com o trabalho artístico vai buscar alternativas para conviver com as leis de mercado, e não fazer dessas leis a baliza fundamental do trabalho criativo.

O teatro de grupo busca um espaço de autonomia, o produtor não pode organizar suas iniciativas pautadas pelos elementos quantitativos, dado que a criação é basicamente instrumentalizada pelos processos qualitativos. Por isso, no teatro de grupo, um teatro de resistência, o produtor não pode se deixar transformar em uma reificação de si mesmo.

Mesmo que nossa época se organize pelos processos de mercantilização, e a indústria cultural seja uma das balizas chaves da contemporaneidade, fazer da produção um modo de prospecção de zonas alternativas é um fazer de instituir procedimentos que criticam a lógica hegemônica. Procedimentos que vão além de uma lógica capitalista baseada, desde 1996, nas Leis de Incentivo Fiscais. O governo de Fernando Henrique Cardoso implanta uma "modernização" nas leis de incentivo à cultura fomentando uma política de parceria entre Estado, empresários e comunidade cultural a nível federal, estadual e municipal e com isso gera uma evolução no comportamento empresarial sobre investimento em cultural.

Com esta "modernização" nas leis de incentivo à cultura surge uma nova modalidade do marketing, é a do Marketing Cultural que é definida pela American Marketing Association como toda ação de marketing que usa a cultura como veículo de comunicação para se difundir o nome, produto ou fixar imagem de uma empresa patrocinadora. Este segmento é muito usado por parte da classe artística como meio de financiar projetos, por outro lado, ele também é muito criticado por esta mesma classe que vê nele apenas um jogo de interesses e mais uma forma da empresa manipular o tipo de cultura financiada com o dinheiro de isenção fiscal.

No entanto, não é apenas uma equação simples de aceitar ou rejeitar tal procedimento, o marketing é um terreno rico de possibilidades e deve ser visto e estudado em sua totalidade, ou seja, ele aborda o mercado e suas relações, tentando construir estratégias de ações para um produto ou serviço, não tem a ver unicamente com publicidade ou venda.

E desta forma a cultura vai cada vez mais entrando no mundo da administração, e os próprios administradores vêem este campo como muito frutífero financeiramente. E tentam vender uma idéia de que gestão sirva para 


\section{Urdimento}

tudo e que mesmo as organizações sem fins lucrativos devem se apropria de formar gerencias de empresas privadas para garantir seu sucesso.

Com isso, inúmeros grupos de teatro que são, originalmente, organizações sem fins lucrativos, passam, com a demanda do mercado e a necessidade de sobrevivência, a adotar modelos de gestão característicos de empresas privadas, transformando assim sua lógica de atuação.

A administração pode ser um forte aliado ao fazer teatral, se focarmos elementos conceituais que servem ao teatro, mesmo sendo um grande desafio aplicá-los. Se partirmos do princípio de que todo grupo de teatro profissional é uma organização com um produto a ser vendido e uma meta a ser alcançada, a utilização de técnicas administrativas nos parece um bom caminho.

Segundo o administrador Idalberto Chiavenato, embora existam variados tipos de organizações, e em cada uma delas tem um objetivo específico, um ramo de atividade particular, dirigentes e pessoas diferentes, os seus problemas internos e externos, o seu mercado, a sua situação financeira, a sua tecnologia, os seus recursos básicos, a sua ideologia e política de negócios, entre outras especificidades, é o administrador que vai solucionar os problemas, dimensionar os recursos, planejar sua aplicação, desenvolver estratégias e efetuar diagnósticos de situações, únicos e exclusivos daquela organização e da sua realidade. "Os princípios gerais relacionados com a tarefa de administrar se aplicam a qualquer tipo ou tamanho de organização" (CHIAVENATO, 1936: 6). Sendo um grupo de teatro uma organização ele também precisa ser administrado adequadamente, para poder realizar seus objetivos com a maior eficácia e economia de ação e recursos. Chiavenato completa que a tarefa de administrar é a de garantir o seguimento da organização.

Toda grande idéia ou projeto artístico pode não dar certo se não for planejado e principalmente administrado. Mais para tanto ele deve contar com um programa de gestão voltado aos interesses artísticos do mesmo, que sim: atinjam o mercado, mais não se vendam ao mercado, ou seja, a arte pode e deve ser uma fonte geradora e distribuidora de renda, por isso é necessário reiterar que os procedimentos do mercado deveriam atender à arte e não o contrário. Diante disto a presença de uma administração não implica em pensar o fazer teatral como pura mercadoria, mas sim como uma ferramenta.

Com isso concluo que o produtor teatral deve ser um fomentador da cultura para os diferentes segmentos da sociedade, mostrando através de seu fazer artístico a importância que o teatro pode ter na vida individual e coletiva. Ele deve procurar abrir espaços para que arte penetre espaços permeáveis do mercado, buscando descobrir formas de convivência, ainda quando estas não sejam harmônicas. 
Ele precisa estar apto para articular a criação artística com o mercado, mantendo sua essência de produtor teatral no que diz respeito ao vinculo e respeito com o público, e com as particularidades estéticas, éticas e sociais de seu projeto artístico.

Isso se dará criando rupturas, como sugere Debord, ou procurando fendas, como propõe Jameson. Mas para isso é preciso que o produtor teatral não se deixe transformar em um produto. É imprescindível que ele seja um agente criativo e comprometido com o trabalho artístico, e se coloque sempre a serviço, primeiramente da arte, para não ser um mero serviçal do mercado. O produtor inserido dentro de um grupo de teatro será capaz de mostrar com o desenvolvimento de seu trabalho a importância que o teatro pode ter na vida individual e coletiva, e o teatro desta forma será capaz de penetrar espaços do mercado, buscando descobrir formas de apropriação e coexistência entre eles.

\section{Referências bibliográficas}

BAUMAN, Zygmi Zygmunt. Modernidade Líquida. Rio de Janeiro: Jorge Zahar Ed., 2001.

CARREIRA, André. O Teatro de grupo e a construção de modelos do ator no Brasil nos anos 80-90. In Anais do IV Congresso Brasileiro de Pesquisa e Pós-Graduação em Artes Cênicas. Rio de Janeiro, maio de 2006: Associação Brasileira de Pesquisa e Pós-Graduação em Artes Cênicas - ABRACE, 2006. p. $75-76$.

DEBORD. Guy. La sociedad del espectáculo. Buenos Aires: Biblioteca de La Mirada, 1995.

DELEUZE, G. Lógica do sentido. 4. ed. Trad. de Luiz Roberto Salinas Fortes. São Paulo: Perspectiva, 1998.

CHIAVENATTO, Idalberto. Introdução à teoria geral da administração. São Paulo: McGraw-Hill, 1936.

FERREIRA. G. M. Teatro de Grupo: revelando e construindo a si mesmo. Trabalho de Conclusão de Curso. (monografia). Universidade do Estado de Santa Catarina, Centro de Artes. Florianópolis, 2001.

FISCHER, E. A necessidade da arte. Trad.Leandro Konder. Rio de Janeiro: Ed. Guanabara, 1987.

JAMESON, Fredric. Pós-Modernismo - A lógica cultural do capitalismo tardio. São Paulo: Ática, 2000.

OLIVEIRA, Valéria; CARREIRA, André. Teatro de grupo: modelo de organização e geração de poéticas. In O Teatro Transcende, ano 12, n. 11, 2003. pp. 95-98. 